\title{
Indications for Caesarean Section and its Fetal and Maternal Outcome in a Teaching Hospital, Province Five, Nepal
}

\author{
Asha Panth ${ }^{1}$, Saraswoti Kumari Gautam Bhattarai ${ }^{2}$, Sunita Acharya ${ }^{3}$ \\ ${ }^{1}$ Teaching Assistant, Nepalgunj Nursing Campus, Tribhuwan University, Institute of Medicine, \\ Nepal \\ ${ }^{2}$ Dean: School of Nursing and Midwifery, Karnali Academy of Health Sciences, Associate \\ Professor Tribhuwan University, Institute of Medicine, Nepal \\ ${ }^{3}$ Lecturer, Nepalgunj Nursing Campus, Tribhuwan University, Institute of Medicine, Nepal
}

Correspondence: Ms. Asha Panth, Email: panth.asha@gmail.com

ABSTRACT

Introduction: Cesarean section (CS) is an operative technique by which a fetus is delivered through an abdominal and uterine incision and is effective in saving maternal and infant lives but caesarean section rates higher than $10 \%$ are not associated with reductions in maternal and newborn mortality rates. The objective of the study was to find out the indications for caesarean section and its fetal and maternal outcomes in a Teaching Hospital, Province Five, Nepal. Methods: A descriptive, cross-sectional study was conducted in a teaching hospital, Nepal. A total of 150 purposively selected postnatal mothers after caesarean section were interviewed by face to face technique using a structured interview schedule. Analysis and interpretation of the findings were done with the help of descriptive and inferential statistics.

Results: The study shows that the majority (93.3\%) of mothers had undergone an emergency caesarean section and the majority (92\%) had maternal indications for caesarean section. Among them, one third had previous caesarean section followed by $14.5 \%$ obstructed labour. Fetal indications include breach (44.4\%), fetal distress (29.6\%), big baby (11.1) and twins and triplets (3.7\%). Only (10.7\%) had an unfavorable fetal outcome which includes the need for Neonatal Intensive Care Unit (NICU) (31.2\%) followed by neonatal death (25\%). Only three mothers (2\%) had unfavorable maternal outcome which includes Post-Partum Hemorrhage (PPH); need for blood transfusion and fever respectively. There was no statistically significant association between socio demographic characteristics and type of caesarean section. There was statistically significant association between the previous history of caesarean section and type of caesarean section $(P=.005)$.

Conclusions: Previous caesarean section was the most common indication for caesarean section. Unfavorable outcome after caesarean section was considerably present which need to be addressed.

Keywords: Caesarean Section, Indications, Maternal Outcome, Fetal Outcome

\begin{tabular}{|c|c|c|}
\hline \multicolumn{2}{|c|}{ Access this article Online } & ArticleInfo. \\
\hline Quick Response Code & Website: & How tocitethisarticle in Vancouver Style? \\
\hline & www.jkahs.org.np & $\begin{array}{l}\text { Panth A,Bhattarai SKG, AcharyaS. Indications } \\
\text { for Caesarean Section and its Fetal and } \\
\text { Maternal Outcome in a Teaching Hospital, } \\
\text { Province Five, Nepal.Karnali Academy of } \\
\text { Health Sciences 2020;3(1):1-11. }\end{array}$ \\
\hline & $\begin{array}{l}\text { DOI: } \\
\text { https://doi.org/10.3126/jkahs.v3i1.28462 } \\
\text { The DOI will be functional after the } \\
\text { issue is fully published online as well } \\
\text { as in printed version }\end{array}$ & $\begin{array}{l}\text { Received: } 2 \text { March, } 2020 \\
\text { Accepted:12 April, } 2020 \\
\text { Published Online:13 April, } 2020 \\
\text { Conflict of Interest: None } \\
\text { Source of Support: None }\end{array}$ \\
\hline
\end{tabular}




\section{INTRODUCTION}

Caesarean section (CS) is an operative technique by which a fetus is delivered through an abdominal and uterine incision. When medically indicated, it is a life-saving procedure for both the mother and the fetus. The rate of caesarean section is increasing in developing countries despite the World Health Organization (WHO) recommendations of $5 \%$ to $15 \%{ }^{1}$. The effects of caesarean section on maternal and perinatal morbidity are still unclear. More research is needed to understand the health effects of caesarean section ${ }^{2}$.

The trends from 150 countries shows that between1990 to $2014,18.6 \%$ of births occur by caesarean section, ranging from $6 \%$ to $27.2 \%$ in the least and most developed regions respectively. The global average caesarean section rate increased by $12.4 \%$ and in Asia (15.1\%) ${ }^{3}$. High caesarean section rate does not improve perinatal outcomes in babies $^{4}$.Caesarean section rates higher than $10 \%$ at the population level are not associated with decrease in maternal and neonatal mortality rates ${ }^{2,5}$.The expansion of the private health sector may be playing a significant role in expansion of caesarean section $^{6,7}$.
Morbidity and mortality from caesarean section is more than in vaginal delivery for both the mother and fetus ${ }^{8-10}$. Routine monitoring of clinical indication of caesarean section in public and private facilities is needed for rational use of the procedure $^{11}$.The unfavorable outcomes of caesarean section are adhesion, excessive blood loss, caesarean hysterectomy, wound infection, dehiscence, still birth, early neonatal death and low birth weight ${ }^{12}$.

There is increasing trend of caesarean section in $\mathrm{Nepal}^{13,}{ }^{14}$. According to Department of Health Services (DOHS) in Nepal, in fiscal year2074/75 deliveries by caesarean section were 17 percent of total institutional deliveries which was above WHO recommendations ${ }^{15}$. The rise in caesarean section rate has been a cause of alarm and needs an in-depth study in $\mathrm{Nepal}^{16}$. Thus, the study was done to find out indications of caesarean section and its fetal and maternal outcome.

\section{MATERIALS AND METHODS}

Descriptive Cross-Sectional study design based on quantitative approach was used in the study. The study was conducted at Nepalgunj Medical College, Teaching 
Hospital, Province Five, Nepal which is the referral level hospital with high patient flow and safe motherhood programme has been launched. The study populations were postnatal mothers after caesarean section and about to discharge from the hospital. Mothers after having vaginal delivery and not willing to participate in the study were excluded in the study. Non probability purposive sampling technique was used.

Prevalence of caesarean section at Nepalgunj Medical College (record of hospital) shows percentage of caesarean section was $24 \%$ of total delivery. Therefore, $\mathrm{p}=0.24, \mathrm{q}=0.76$

The sample size was calculated by using Cochran's formula ${ }^{19}$

$\mathrm{N}=\mathrm{Z}^{2} \mathrm{pq} / \mathrm{l}^{2}$ with the desired precision of $7 \%$

Standard normal deviate $(\mathrm{z})=1.96$

Absolute allowable error $(\mathrm{l})=0.07$

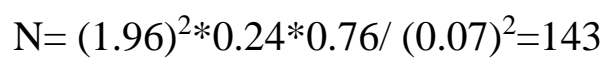

To reduce non response rate, additional 5\% was taken so, $5 \%$ of $143=7.15$

Final sample size was 150

Structured interview based questionnaire was used to collect the data which was developed by the researchers themselves based on literature and consultation with expertise.

The content validity of the test instrument was established by consulting with advisors, subject matter experts, and literature review.
Pretesting of the instrument was done among $10 \%$ mothers admitted in maternity unit of Nepalgunj Medical College and those pretested respondents were excluded from the study. The instrument was translated in Nepali language and then retranslated back to English to retain the same meaning. Data was collected through face to face interview technique and the record review from the mother's file by the researchers from January 92020 to First March 2020.

Ethical approval was taken from Institutional Review Committee (IRC) of Nepalgunj Medical College, Teaching Hospital (Ref no. 451/076/077). Informed consent was obtained from the participants and they were given liberty to discontinue participating in the study if they wish. Precaution was taken throughout the study in every step to safeguard the right and welfare of all respondents in the study and confidentiality was maintained. The collected data were checked for completeness, edited, coded and entered in SPSS version 20 for analysis. Descriptive statistics (frequency, percentage, mean, range and standard deviation) and inferential statistics (Chie square test, Odd ratio) were done and interpreted as per findings. 


\section{RESULTS}

Results were obtained from total of 150 postnatal mothers after caesarean section. As shown in Table1a, one third (33.3\%) of the mothers were between 20-24 years of age, 8.7 \% were below 20 and only (6.0\%) were 35 years and above. Regarding ethnicity, more than half (54\%) of the mothers belong to Brahmin/ Chhetri followed by 30\% Janjati. In regards to type of family, half of the mothers (50.7\%) were living in nuclear family and other half in joint family. Likewise, all the mothers were married.

Table 1a: Socio demographic Characteristics of Mothers: Age, Ethnicity, Type of Family, Marital status

\begin{tabular}{|c|c|c|}
\hline Socio demographic Characteristics & Number & Percentage \\
\hline \multicolumn{3}{|l|}{ Age(in years) } \\
\hline$<20$ & 13 & 8.7 \\
\hline $20-24$ & 50 & 33.3 \\
\hline $25-29$ & 44 & 29.3 \\
\hline $30-34$ & 34 & 22.7 \\
\hline 35 and above 35 & 9 & 6.0 \\
\hline \multicolumn{3}{|l|}{$\begin{array}{l}\text { Mean age }=26 \text { years } \\
\text { S.D. }= \pm 4.995 \text { Years } \\
\text { Range }=17-38 \text { years }\end{array}$} \\
\hline \multicolumn{3}{|l|}{ Ethnicity } \\
\hline Brahmin/Chhetri & 81 & 54.0 \\
\hline Janajati & 45 & 30.0 \\
\hline Dalit & 20 & 13.3 \\
\hline Madhesi & 4 & 2.7 \\
\hline \multicolumn{3}{|l|}{ Type of family } \\
\hline Nuclear & 76 & 50.7 \\
\hline Joint & 74 & 49.3 \\
\hline \multicolumn{3}{|l|}{ Marital Status } \\
\hline Married & 150 & 100.0 \\
\hline
\end{tabular}


Table 1 b: Socioeconomic Characteristics of Mothers: Educational status, Occupation, Religion, Family Income Status

\begin{tabular}{|c|c|c|}
\hline Socio Economic Characteristics & Number & Percentage \\
\hline \multicolumn{3}{|l|}{ Educational Status(n=150) } \\
\hline Illiterate & 1 & 0.7 \\
\hline Literate & 149 & 99.3 \\
\hline \multicolumn{3}{|l|}{ Educational level(n=149) } \\
\hline Primary level & 16 & 10.7 \\
\hline Secondary level & 86 & 57.7 \\
\hline Higher secondary level & 38 & 25.5 \\
\hline Higher education & 9 & 6.0 \\
\hline \multicolumn{3}{|l|}{ Occupation (n=150) } \\
\hline Agriculture & 11 & 6.2 \\
\hline Homemaker & 113 & 63.8 \\
\hline Business & 9 & 5.1 \\
\hline Service & 14 & 7.9 \\
\hline Student & 3 & 1.7 \\
\hline \multicolumn{3}{|l|}{ Religion (n=150) } \\
\hline Hinduism & 145 & 96.7 \\
\hline Christianity & 5 & 3.3 \\
\hline \multicolumn{3}{|l|}{ Family Income Status $(\mathrm{n}=150)$} \\
\hline Enough for less than six months & 1 & 0.7 \\
\hline Enough for less than one year & 73 & 48.7 \\
\hline Enough for one year and surplus & 76 & 50.7 \\
\hline
\end{tabular}

As shown in Table 1b, almost all (99.3\%) of mothers were literate. Among literate, 57.7\% were secondary level and only (6.0\%) were higher education. Likewise, most (63.8\%) of the mothers were homemaker. Similarly, majority of the mothers (96.7\%) were Hindu and only 3.3\% were Christian. Half of the mothers (50.7\%) had household income enough for one year and surplus. 
Table 2a: Obstetric Characteristics of Mothers: Parity, Planned Pregnancy, ANC visits, Weeks of gestation

\begin{tabular}{|c|c|c|}
\hline Obstetric Characteristics & Number & Percentage \\
\hline \multicolumn{3}{|l|}{ Parity } \\
\hline Primiparous & 70 & 46.7 \\
\hline Second para & 56 & 37.3 \\
\hline Third para & 19 & 12.7 \\
\hline Fourth para & 4 & 2.7 \\
\hline More than fourth para & 1 & 0.7 \\
\hline \multicolumn{3}{|l|}{ Planned Pregnancy } \\
\hline Yes & 145 & 96.7 \\
\hline No & 5 & 3.3 \\
\hline \multicolumn{3}{|l|}{ ANC visits } \\
\hline Yes & 149 & 99.3 \\
\hline No & 1 & 0.7 \\
\hline \multicolumn{3}{|l|}{ No. of ANC Visits $(n=149)$} \\
\hline Less than 4 times & 15 & 10.1 \\
\hline Four times & 128 & 85.9 \\
\hline More than 4 times & 6 & 4.0 \\
\hline \multicolumn{3}{|l|}{ Weeks of gestation } \\
\hline Below 37 & 17 & 11.3 \\
\hline $37-42$ & 128 & 85.3 \\
\hline Above 42 & 5 & 3.3 \\
\hline
\end{tabular}

As shown in Table 2a, less than half (46.7\%) of the mothers were primiparous. Likewise, majority (96.7\%) of the mothers reported that their pregnancy was planned. Regarding Antenatal visits, almost all (99.3\%) of the mothers had visited ANC and majority (85.9\%) of mothers had visited ANC for four times. Likewise, majority (85.3\%) were at 37-42 weeks of gestation. 
Table 2b: Obstetric Characteristics of Mothers: History of abortion, still birth, previous history, type of caesarean section, Pregnancy Complication, weight, sex of baby

\begin{tabular}{|c|c|c|}
\hline Obstetric Characteristics & Number & Percentage \\
\hline \multicolumn{3}{|l|}{ History of abortion } \\
\hline Yes & 27 & 18.0 \\
\hline No & 123 & 82.0 \\
\hline \multicolumn{3}{|l|}{ No. of Abortion (n=27) } \\
\hline One & 21 & 77.8 \\
\hline Two & 4 & 14.8 \\
\hline Three or more & 2 & 7.4 \\
\hline \multicolumn{3}{|l|}{ History of still birth } \\
\hline Yes & 2 & 1.3 \\
\hline No & 148 & 98.7 \\
\hline \multicolumn{3}{|l|}{ Previous history of caesarean } \\
\hline Yes & 42 & 23.7 \\
\hline No & 108 & 61.0 \\
\hline \multicolumn{3}{|l|}{ Complications during pregnancy } \\
\hline Yes & 16 & 10.7 \\
\hline No & 134 & 89.3 \\
\hline \multicolumn{3}{|l|}{ Type of complication (n=16) } \\
\hline Ante partum Hemorrhage (APH) & 4 & 25.0 \\
\hline Pregnancy Induced Hypertension (PIH) & 11 & 68.8 \\
\hline Severe vomiting & 1 & 6.2 \\
\hline \multicolumn{3}{|l|}{ Type of caesarean section } \\
\hline Elective & 10 & 6.7 \\
\hline Emergency & 140 & 93.3 \\
\hline \multicolumn{3}{|l|}{ Sex of Recent Baby (n=153) } \\
\hline Male & 93 & 60.78 \\
\hline Female & 60 & 39.21 \\
\hline \multicolumn{3}{|l|}{ Birth weight of baby in $\mathrm{Kg}(\mathrm{n}=153)$} \\
\hline Below 2.5 & 28 & 18.3 \\
\hline 2.5-3.5 & 109 & 71.24 \\
\hline Above 3.5 & 16 & 10.46 \\
\hline
\end{tabular}

Table $2 \mathrm{~b}$ revealed that only $18 \%$ of mothers had history of abortion. Among them, most (77.8\%) of the mothers had single history of abortion and only $1.3 \%$ had history of still birth. Only $23.7 \%$ of mothers had previous history of caesarean section. Only $10.7 \%$ of the mothers had complication during pregnancy. Majority (93.3\%) of mothers had undergone emergency caesarean section and only (6.7\%) had elective caesarean section. Regarding sex of the recent baby, most (60.78\%) were male and 39.21\% were female. Most (71.24\%) of the babies weight was within normal range i.e. 2.5 to $3.5 \mathrm{~kg}$. 
Table 3: Indications for Caesarean Section

\begin{tabular}{|c|c|c|}
\hline Indications* & Number & Percentage \\
\hline \multicolumn{3}{|l|}{ Fetal Indications(n=27) } \\
\hline Fetal Distress & 8 & 29.6 \\
\hline Intra Uterine Growth Retardation (IUGR) & 2 & 7.4 \\
\hline Big Baby & 3 & 11.1 \\
\hline Twins & 1 & 3.7 \\
\hline Breech & 12 & 44.4 \\
\hline Triplet & 1 & 3.7 \\
\hline \multicolumn{3}{|l|}{ Maternal Indications(n=138) } \\
\hline Contracted Pelvis & 8 & 5.8 \\
\hline Placenta Praevia & 4 & 2.9 \\
\hline Pregnancy Induced Hypertension & 6 & 4.3 \\
\hline Previous Caesarean section & 43 & 31.2 \\
\hline Poly/Oligohydraminous & 15 & 10.9 \\
\hline Early Membrane Rupture & 3 & 2.2 \\
\hline Prolonged Labour & 11 & 8.0 \\
\hline Meconium Stained liquor & 13 & 9.4 \\
\hline Preeclampsia/ Eclampsia & 9 & 6.5 \\
\hline Obstructed Labour & 20 & 14.5 \\
\hline Gestational Diabetes Mellitus (GDM) & 1 & 0.7 \\
\hline Non Progress Of Labour (NPOL) & 2 & 1.4 \\
\hline Failed Induction & 3 & 2.2 \\
\hline
\end{tabular}

*Multiple Responses

Regarding indications, majority (92\%) of mothers had maternal indications for caesarean section and only $18 \%$ had fetal indications. One third (31.2\%) was previous caesarean section as maternal indications for caesarean section followed by $14.5 \%$ obstructed labour. Fetal indications for caesarean section were $44.4 \%$ breech followed by fetal distress $29.6 \%$ (Table 3). 
Table 4: Fetal and Maternal Outcome after Caesarean Section

\begin{tabular}{|c|c|c|}
\hline Outcome & Number & Percentage \\
\hline \multicolumn{3}{|l|}{ Fetal Outcome } \\
\hline Unfavorable & 16 & 10.7 \\
\hline Favorable & 134 & 89.3 \\
\hline \multicolumn{3}{|l|}{ Unfavorable Fetal Outcome $(n=16)$} \\
\hline Birth asphyxia & 1 & 6.2 \\
\hline Neonatal death & 4 & 25.0 \\
\hline Low APGAR & 3 & 18.8 \\
\hline Need for NICU & 5 & 31.2 \\
\hline Difficulty feeding & 2 & 12.5 \\
\hline Eye infection & 1 & 6.2 \\
\hline \multicolumn{3}{|l|}{ Maternal Outcome } \\
\hline Unfavorable & 3 & 2.0 \\
\hline Favorable & 147 & 98.0 \\
\hline \multicolumn{3}{|l|}{ Unfavorable Maternal outcome $(n=3)$} \\
\hline Postpartum hemorrhage (PPH) & 1 & 33.3 \\
\hline Need for blood transfusion & 1 & 33.3 \\
\hline Fever & 1 & 33.3 \\
\hline
\end{tabular}

As shown in table 4, only (10.7\%) of mothers had unfavorable fetal outcome, which included 31.2\% need for NICU followed by 25\% neonatal deaths. Only three mothers (2\%) had unfavorable maternal outcome including PPH, need for blood transfusion and fever respectively. 
Table 5: Association between Socio demographic Characteristics of Mothers and Caesarean Section

\begin{tabular}{|c|c|c|c|c|}
\hline \multicolumn{5}{|c|}{ Type of caesarean section } \\
\hline Variables & $\begin{array}{l}\text { Elective } \\
\text { N (\%) }\end{array}$ & $\begin{array}{l}\text { Emergency } \\
\text { N (\%) }\end{array}$ & $P$ value & $\begin{array}{l}\text { Unadjusted OR } \\
95 \% \text { CI }\end{array}$ \\
\hline \multicolumn{5}{|l|}{ Age } \\
\hline Below 25 & $2(3.2 \%)$ & 61(96.8\%) & $.193^{a}$ & $.324(.066-1.580)$ \\
\hline 25 and above & $8(9.2 \%)$ & 79(90.8\%) & & 1 \\
\hline \multicolumn{5}{|l|}{ Ethnicity } \\
\hline Brahmin/Chhetri & $6(7.4 \%)$ & 75(92.6\%) & $1.000^{a}$ & $1.220(.329-4.519)$ \\
\hline Others & $4(6.2 \%)$ & 75(92.6\%) & & 1 \\
\hline \multicolumn{5}{|l|}{ Type of family } \\
\hline Nuclear & $7(9.2 \%)$ & $69(90.8 \%)$ & $.327^{a}$ & 2..401(.597-9.664) \\
\hline Joint & $3(4.1 \%)$ & 71(95.9\%) & & 1 \\
\hline \multicolumn{5}{|l|}{ Educational level } \\
\hline Up to secondary & $8(7.8 \%)$ & 94(92.2\%) & $.506^{a}$ & 1.915(.391-9.387) \\
\hline $\begin{array}{l}\text { Higher secondary } \\
\text { and above }\end{array}$ & $2(4.3 \%)$ & $45(95.7 \%)$ & & 1 \\
\hline \multicolumn{5}{|l|}{ Occupation } \\
\hline Homemaker & $8(7.1 \%)$ & 105 (92.9\%) & $1.000^{a}$ & $1.219(.246-6.033)$ \\
\hline Others & $2(5.9 \%)$ & 32(94.1\%) & & 1 \\
\hline \multicolumn{5}{|l|}{ Family Income Status } \\
\hline $\begin{array}{l}\text { One year and } \\
\text { Surplus }\end{array}$ & $6(7.9 \%)$ & 70(92.1\%) & $.746^{a}$ & $1.500(.406-5.547)$ \\
\hline Less than One year & $4(5.4 \%)$ & $70(94.6 \%)$ & & 1 \\
\hline
\end{tabular}

Pearson's Chi-Square test, ${ }^{a} F$ isher Exact Test, ${ }^{*} P$ value significant at $<0.05$ level, 1 Reference

In this study, there was no statistically significant association between socio demographic characteristics and type of caesarean section (Table 5). 
Table 6: Association between Obstetric Characteristics of Mothers and Caesarean Section

\begin{tabular}{|c|c|c|c|c|}
\hline \multicolumn{5}{|c|}{ Type of Caesarean Section } \\
\hline Variables & Elective & Emergency & $\begin{array}{c}\mathbf{P} \\
\text { value }\end{array}$ & $\begin{array}{l}\text { Unadjusted OR } \\
\text { 95\% Confidence } \\
\text { Interval }\end{array}$ \\
\hline \multicolumn{5}{|l|}{ Parity } \\
\hline$\leq$ Second para & $8(6.3 \%)$ & $118(93.7 \%)$ & $.662^{\mathrm{a}}$ & $.746(.148-3.749)$ \\
\hline$>$ Second para & $2(8.3 \%)$ & $22(91.7 \%)$ & & 1 \\
\hline \multicolumn{5}{|l|}{ No. of ANC } \\
\hline$\leq 4$ times & $9(6.3 \%)$ & 134(93.7\%) & $.346^{\mathrm{a}}$ & $.336(.035-3.188)$ \\
\hline$>4$ times & $1(16.7 \%)$ & $5(83.3 \%)$ & & 1 \\
\hline \multicolumn{5}{|c|}{ Weeks of gestation } \\
\hline Below 37 & $2(11.8 \%)$ & $15(88.2 \%)$ & $.316^{\mathrm{a}}$ & $2.083(.404-10.734)$ \\
\hline 37 and above & $8(6.0 \%)$ & $125(94.0 \%)$ & & 1 \\
\hline \multicolumn{5}{|c|}{$\begin{array}{l}\text { History of caesarean } \\
\text { section }\end{array}$} \\
\hline Yes & $7(16.7 \%)$ & 35(83.3\%) & $.005^{\mathrm{a} *}$ & 7.000(1.717-28.545) \\
\hline No & $3(2.8 \%)$ & 105(97.2\%) & & 1 \\
\hline \multicolumn{5}{|c|}{ History of abortion } \\
\hline Yes & $2(7.4 \%)$ & $25(92.6 \%)$ & $1.000^{a}$ & $1.150(.230-5.746)$ \\
\hline No & $8(6.5 \%)$ & $115(93.5 \%)$ & & 1 \\
\hline \multicolumn{5}{|c|}{$\begin{array}{l}\text { Complications during } \\
\text { pregnancy }\end{array}$} \\
\hline No & $9(6.7 \%)$ & 125(93.3\%) & $1.000^{\mathrm{a}}$ & $1.080(.128-9.127)$ \\
\hline Yes & $1(6.2 \%)$ & $15(93.8 \%)$ & & 1 \\
\hline \multicolumn{5}{|l|}{ Weight of baby } \\
\hline Above 3.5 & $3(18.8 \%)$ & $13(81.2 \%)$ & $.075^{a}$ & 4.187(.965-18.173) \\
\hline Below 3.5 & $7(5.2 \%)$ & $127(94.8 \%)$ & & 1 \\
\hline
\end{tabular}

Pearson's Chi- Square test, *P value significant at $<0.05$ level, ${ }^{a}$ Fisher Exact test,

1Reference

In this study, there was statistically

baby with birth weight above $3.5 \mathrm{~kg}$ were significant association between the previous history of caesarean section and type of caesarean section $(P=.005)$ (Table 6). Although insignificant in other 4.187 times more likely to have elective caesarean section than those with birth weight below 3.5 $\operatorname{kg}(P=.075 ; \mathrm{OR}=4.187 ; \mathrm{CI}=.965-18.173)$. variables, those mothers who were below 37 weeks of gestation were 2.083 times more likely to have elective caesarean section than above 37 weeks $(P=.316$; $\mathrm{OR}=2.083 ; \quad \mathrm{CI}=.404-10.734)$. Likewise, 


\section{DISCUSSION}

In this study, majority (93.3\%) of mothers had undergone emergency caesarean section and only (6.7\%) had elective caesarean section. Similarly, the study conducted in Nigeria showed that emergency caesarean section was $74.6 \%$, while elective caesarean section was $25.6 \%{ }^{7}$. Likewise, nearly one third (31.2\%) had previous caesarean section as maternal indications for caesarean section followed by $14.5 \%$ obstructed labour,10.9\% as poly/oligohydraminous, $9.4 \%$ as meconium stained liquor and only (1.4\%) as non progress of labour. The study shows that $44.4 \%$ was breech as fetal indications for caesarean section followed by $29.6 \%$ fetal distress. In consistent with the study, the study conducted in Nepal Medical College Teaching Hospital showed that slow progression of labour, previous caesarean section, fetal distress and breech presentation were the first four common indications of caesarean delivery ${ }^{14}$.

Another study done in England showed that breech presentation and previous caesarean section were associated with an increased risk of caesarean section ${ }^{17}$. Also, the study conducted in Nigeria showed obstructed labour, fetal distress were the causes for caesarean section4. In contrast to the study, the study conducted in B.P. Koirala Institute of Health Sciences showed that the most common indication for caesarean section was
23.4\% meconium- stained liquor, 17.2\% previous caesarean section followed by $11.1 \%$ breech, 9.6\% fetal distress and 7.2\% nonprogress of labor ${ }^{13}$.

Regarding outcome after caesarean section, only $(10.7 \%)$ of mothers had unfavorable fetal outcome. Among them, 31.2\% of babies need NICU followed by 4(25\%) neonatal death, 18.8\% low APGAR and only 6.2\% have birth asphyxia and eye infection. Also the study shows that only 3 (2\%) mothers have unfavorable maternal outcome which include $\mathrm{PPH}$, need for blood transfusion and fever respectively. This finding is in consistent with the study conducted in Ethiopia showed that the maternal complications was excessive blood loss (5.6\%),fetal complication after caesarean section was early neonatal death (2.4\%), low birth weight (17.2\%), and low APGAR score $(20.4 \%)^{12}$. In contrast to the study, the study conducted in Nepal Medical College Teaching Hospital showed that the incidence of complication was $23.9 \%$ of all deliveries and postpartum hemorrhage was (69.2\%). Three babies had APGAR score less than 3 and there were 2 neonatal deaths after caesarean delivery ${ }^{14}$.

In this study, there was no statistically significant association between socio demographic characteristics and type of caesarean section. In contrast to the study, the study done in Oman showed that increased 
age (above 25 years) was significantly associated with increased risk of cesarean section ${ }^{18}$. Another study conducted in England showed that increasing maternal age was independently associated with $\mathrm{CS}^{17}$.

In this study, there was statistically significant association between the previous history of caesarean section and type of caesarean section $(P=.005)$. Although insignificant in other variables, those mothers who were below 37 weeks of gestation were 2.083 times more likely to have elective caesarean section than above 37 weeks $(P=.316 ; \mathrm{OR}=2.083$; $\mathrm{CI}=.404-10.734)$. Likewise, baby with birth weight above $3.5 \mathrm{~kg}$ were 4.187 times more likely to have elective caesarean section than those with birth weight below $3.5 \mathrm{~kg}(P=.075$; $\mathrm{OR}=4.187 ; \mathrm{CI}=.965-18.173) . \quad$ In consistent with the study, the study conducted in England showed that previous caesarean section, extremes of neonatal birth weight was associated with caesarean section. But in contrast to the study, increasing parity was associated with decrease of elective caesarean section $^{14}$.

\section{CONCLUSION}

Majority of mothers had emergency caesarean section with previous caesarean section being the main indication. Unfavorable outcome after caesarean section included need for NICU, neonatal death, low APGAR, difficulty feeding, birth asphyxia, eye infection, PPH, need for blood transfusion and fever which need to be decreased by increasing quality of service.

\section{Acknowledgement}

We would like to express gratitude to Nepalgunj Medical College, Teaching Hospital for providing the golden opportunity to carry out this study.

\section{REFERENCES}

1. Tsega F, Mengistie B, Dessie Y, Mengesha $M$. Prevalence of cesarean section in urban health facilities and associated factors in Eastern Ethiopia: hospital based cross sectional study. J Preg Child Health. 2015;2(3):169-73. [Google Scholar] [Research Gate]

2. WHO Statement on caesarean section rates. Reproductive health matters. 2015 May; 23(45):149. [Google Scholar]_[PubMed]

3. Betrán AP, Ye J, Moller AB, Zhang J, Gülmezoglu AM, Torloni MR. The increasing trend in caesarean section rates: global, regional and national estimates: 1990-2014. PloS one. 2016 Feb 5; 11(2):e0148343. [Google Scholar] [ Pub Med]

4. Ugwa E, Ashimi A, Abubakar MY. Caesarean section and perinatal outcomes in a sub-urban tertiary hospital in North-West Nigeria. Nigerian medical journal: journal of the Nigeria Medical Association. 2015 May; 56(3):180.[Google scholar]

5. Ye J, Zhang J, Mikolajczyk R, Torloni MR, Gülmezoglu AM, Betran AP. Association between rates of caesarean section and maternal and neonatal mortality in the 21st century: a worldwide population-based ecological study with longitudinal data. BJOG: An International Journal of Obstetrics \&Gynecology. 2016 Apr; 123(5):745-53.

[Google Scholar] [Pub Med]

6. Beogo I, Rojas BM, Gagnon MP. Determinants and materno-fetal outcomes related to cesarean section delivery in private and public hospitals in low-and middle-income countries: a systematic review and meta-analysis protocol. Systematic reviews. 2017 Dec;6(1):5. [ Google Scholar] [ Full Text] 
7. Maanongun MT, Ornguze AA, Ojabo AO. Indications and the materno-foetal outcome of caesarean section in a secondary health facility in obudu, south-south Nigeria. Res Rep Gynaecol Obstet. 2017; 1 (3): 4-9 Res Rep Gynaecol Obstet 2017 Volume 1 Issue. 2017; 3. [Google Scholar]

8. Villar J, Carroli G, Zavaleta N, Donner A, Wojdyla D, Faundes A, Velazco A, Bataglia V, Langer A, Narváez A, Valladares E. Maternal and neonatal individual risks and benefits associated with caesarean delivery: multicentre prospective study. Bmj. 2007 Nov 15; 335(7628):1025.

[Google Scholar ] [Pub Med]

9. Silver RM, Landon MB, Rouse DJ, Leveno KJ, Spong CY, Thom EA, Moawad AH, Caritis SN, Harper M, Wapner RJ, Sorokin Y. Maternal morbidity associated with multiple repeat cesarean deliveries. Obstetrics \& Gynecology. 2006 Jun 1; 107(6):122632.[Google Scholar] [Pub Med]

10. Subedi S. Rising rate of cesarean section-A year review. Journal of Nobel Medical College. 2011; 1(2):50-6. [Google Scholar]

11. Begum T, Rahman A, Nababan H, Hoque DM, Khan AF, Ali T, Anwar I. Indications and determinants of caesarean section delivery: evidence from a population-based study in Matlab, Bangladesh. PloS one. 2017 Nov 20; 12(11):e0188074.

[Google Scholar]

12. Mengesha, M.B., Adhanu, H.H., Weldegeorges, D.A. et al. Maternal and fetal outcomes of cesarean delivery and factors associated with its unfavorable management outcomes; in Ayder Specialized Comprehensive Hospital, Mekelle, Tigray, Ethiopia, 2017. BMC Res Notes 12, 650 (2019) doi: 10.1186/s13104-019-4690-5.[ Google Scholar]

13. Chhetri S, Singh U. Caesarean section: its rates and indications at a tertiary referral center in Eastern Nepal. Health Renaissance. 2011; 9(3):179-83. [Google Scholar]

14. Khanal R. Caesarean delivery at Nepal Medical College Teaching Hospital, Kathmandu, Nepal. Nepal Medical College journal: NMCJ. 2004 Jun; 6(1):53-5. [Google Scholar]

15. Annual Report: Department of Health Services (DOHS), Nepal, 2074/75.Retrieved from [Link]

16. Prasad A, Bhandari G, Saha R. Profile of Caesarean Section at Kathmandu Medical College. Journal of
Nepal Health Research Council. 2017 Sep 15; 15(2):110-3. [Google Scholar]

17. Patel RR, Peters TJ, Murphy DJ. Prenatal risk factors for Caesarean section. Analyses of the ALSPAC cohort of 12944 women in England. International journal of epidemiology. 2005 Apr 1; 34(2):353-67. [Google Scholar]

18. Al Busaidi I, Al-Farsi Y, Ganguly S, Gowri V. Obstetric and non-obstetric risk factors for cesarean section in Oman. Oman medical journal. 2012 Nov; 27(6):478. [ [Pub Med]

19. Cochran WG. Sampling techniques. John Wiley \& Sons; 2007;1-21. [Link] 